\title{
Therapeutic Targeting of Epithelial Plasticity Programs: Focus on the Epithelial-Mesenchymal Transition
}

\author{
Reem Malek $^{a}$ Hailun Wang ${ }^{a}$ Kekoa Taparra ${ }^{a, d}$ Phuoc T. Tran ${ }^{a-d}$ \\ Departments of ${ }^{a}$ Radiation Oncology and Molecular Radiation Sciences and ${ }^{b}$ Oncology, Sidney Kimmel \\ Comprehensive Cancer Center, ${ }^{C}$ Department of Urology, and ${ }^{\mathrm{d}}$ Program in Cellular and Molecular Medicine, \\ Johns Hopkins University School of Medicine, Baltimore, MD, USA
}

\section{Keywords \\ Epithelial-mesenchymal transition - Tumor plasticity . \\ HoxA9 - Glycosylation · Hexosamine biosynthetic pathway $\cdot$ Immunotherapy Epigenetic therapy $\cdot$ O-linked $\beta$ - $N$-acetylglucosamine}

\begin{abstract}
Mounting data points to epithelial plasticity programs such as the epithelial-mesenchymal transition (EMT) as clinically relevant therapeutic targets for the treatment of malignant tumors. In addition to the widely realized role of EMT in increasing cancer cell invasiveness during cancer metastasis, the EMT has also been implicated in allowing cancer cells to avoid tumor suppressor pathways during early tumorigenesis. In addition, data linking EMT to innate and acquired treatment resistance further points towards the desire to develop pharmacological therapies to target epithelial plasticity in cancer. In this review we organized our discussion on pathways and agents that can be used to target the EMT in cancer into 3 groups: (1) extracellular inducers of EMT, (2) the transcription factors that orchestrate the EMT transcriptome, and (3) the downstream effectors of EMT. We highlight only briefly specific canonical pathways known to be involved in EMT, such as the signal transduction pathways
\end{abstract}

\begin{tabular}{ll}
\hline KARGER & $\begin{array}{l}\text { ( } 2017 \text { The Author(s) } \\
\text { Published by S. Karger AG, Basel }\end{array}$ \\
$\begin{array}{l}\text { E-Mail karger@karger.com } \\
\text { www.karger.com/cto }\end{array}$ & $\begin{array}{l}\text { This article is licensed under the Creative Commons Attribution- } \\
\text { NonCommercial-NoDerivatives 4.0 International License (CC BY- } \\
\text { NC-ND) (http://www.karger.com/Services/OpenAccessLicense) } \\
\text { Usage and distribution for commercial purposes as well as any dis- } \\
\text { tribution of modified material requires written permission. }\end{array}$
\end{tabular}

TGF $\beta$, EFGR, and Axl-Gas6. We emphasize in more detail pathways that we believe are emerging novel pathways and therapeutic targets such as epigenetic therapies, glycosylation pathways, and immunotherapy. The heterogeneity of tumors and the dynamic nature of epithelial plasticity in cancer cells make it likely that targeting only 1 EMT-related process will be unsuccessful or only transiently successful. We suggest that with greater understanding of epithelial plasticity regulation, such as with the EMT, a more systematic targeting of multiple EMT regulatory networks will be the best path forward to improve cancer outcomes.

(c) 2017 The Author(s)

Published by S. Karger AG, Basel

\section{Introduction}

There is an ever-growing body of evidence nominating epithelial plasticity programs such as the epithelial-mesenchymal transition (EMT) as ideal, clinically relevant targets for the treatment of malignant tumors - both primary and metastatic [van Denderen and Thompson,

R.M. and H.W. contributed equally to this work.
Phuoc T. Tran, MD, PhD

Department of Radiation Oncology and Molecular Radiation Sciences Sidney Kimmel Comprehensive Cancer Center, Johns Hopkins Hospital 1550 Orleans Street, CRB2 Rm 406, Baltimore, MD 21231 (USA)

E-Mail tranp@jhmi.edu 


\begin{tabular}{|c|c|}
\hline \multicolumn{2}{|c|}{ Abbreviations used in this paper } \\
\hline 5 -aza & 5-azacytidine or 5-aza-2'-deoxycytidine \\
\hline 5SGlcNAc & 5-thioglucosamine \\
\hline CpG & cytosine-guanine \\
\hline DNMT & DNA methyltransferase \\
\hline ECM & extracellular matrix \\
\hline EMT & epithelial-mesenchymal transition \\
\hline GSK & glycogen synthase kinase \\
\hline HDACs & histone deacetylases \\
\hline LSD1 & lysine-specific demethylase 1 \\
\hline miRNAs & micro RNAs \\
\hline MMP & matrix metalloproteinase \\
\hline O-GlcNAc & O-linked $\beta$ - $N$-acetylglucosamine \\
\hline OGT & O-GlcNAc transferase \\
\hline OSCC & oral squamous cell carcinoma \\
\hline STAT3 & signal transducer and activator of transcription 3 \\
\hline TF & transcription factor \\
\hline UCH-L1 & ubiquitin C-terminal hydrolase-L1 \\
\hline
\end{tabular}

2013; Davis et al., 2014b]. In addition to the widely realized role of EMT in increasing cancer cell motility and invasiveness during cancer metastasis, the EMT has also been implicated in allowing cancer cells to avoid tumor suppressor pathways of apoptosis, anoikis, and cellular senescence during tumorigenesis [Sanchez-Tillo et al., 2012; Tiwari et al., 2012]. Moreover, the observation that cancer cells surviving treatment are enriched in EMT markers and the preclinical data linking EMT to innate treatment resistance enhances the need to develop new pharmacological therapies to target epithelial plasticity in cancer [Davis et al., 2014b]. Despite advances in the basic and translational understanding of the EMT (many of which are reviewed in the accompanying articles in this current issue), key questions remain regarding the benefit and practicality of targeting EMT in cancer patients. Many of these key issues have been discussed previously and we refer readers to these excellent references: van Denderen and Thompson [2013], Davis et al. [2014b]. In this review we will concentrate primarily on pathways and agents that can be used to target the EMT in cancer.

We have organized our review of this subject into 3 broad groups classified based on their spatial and temporal role during EMT: (1) extracellular inducers of EMT, (2) the transcription factors that orchestrate the EMT transcriptome, and finally (3) the downstream molecular effectors of EMT (Fig. 1). We have also chosen to structure our review so as to highlight only briefly specific canonical pathways known to be involved in EMT and potential therapeutic agents for these canonical pathways

Agents That Target EMT (e.g., signal transduction pathways such TGF $\beta$, EFGR, and Axl-Gas6). At the same time, we aimed to introduce in more detail pathways that we believe are emerging novel pathways and therapeutic targets or that in our opinion deserve greater attention, i.e., epigenetic therapies, glycosylation pathways, and immunotherapy.

\section{Targeting Extracellular Inducers That Initiate the EMT Program}

Many signals from the tumor microenvironment can induce EMT in cancer cells. These signals include paracrine-autocrine soluble mediators such as growth factors and cytokines, hypoxia, and extracellular matrix (ECM) components and biophysical properties of the ECM, such as stiffness [Lester et al., 2007; Lo et al., 2007; Polyak and Weinberg, 2009; Yadav et al., 2011].

The primary autocrine-paracrine inducers of EMT are from the TGF $\beta$, BMP, and other growth factor (EGF, HGF, IGF, and FGF) signal transduction pathway families [Lamouille et al., 2014]. Potential inhibitors of EMT inducers have been identified using high-throughput drug screening. For example, connectivity mapping using global gene expression profiles of TGF $\beta$-induced EMT was used to identify rapamycin and 17-AAG as potential inhibitors of EMT [Reka et al., 2011]. Furthermore, inhibitors of ALK5, MEK, and SRC were shown to inhibit EMT downstream of EGF, HGF, and IGF-1 [Reka et al., 2011; Chua et al., 2012]. We will only briefly highlight further examples of molecules targeting these pathways below.

\section{TGF $\beta$ Pathway}

The most well-known inducer of EMT remains TGF $\beta$ (transforming growth factor beta) and there is considerable interest in the inhibition of TGF $\beta$ signaling as a strategy to inhibit EMT-induced tumor cell invasion and dissemination. Several inhibitors in the preclinical pipeline have been identified. SB431542 can inhibit TGF $\beta$ R kinase, thus blocking TGF $\beta$-induced EMT in pancreatic cancer cells [Halder et al., 2005]. SD-093 and LY-580276 are competitive inhibitors for the ATP-binding site of TGF $\beta$ RI kinase. These drugs blocked EMT and cancer cell migration in many cell types [Subramanian et al., 2004; Peng et al., 2005]. More recently, specific TGF $\beta$ inhibitors, EW-705, EW-7195, and EW-7197, have been shown to disrupt EMT in TGF $\beta$-treated breast cancer cells as well as in vivo using the 4T1 orthotopic xenograft mouse model [Nagaraj and Datta, 2010; Park et al., 2011a, b]. 
Fig. 1. Potential therapeutic targets arranged based on their spatial-temporal roles during the EMT.

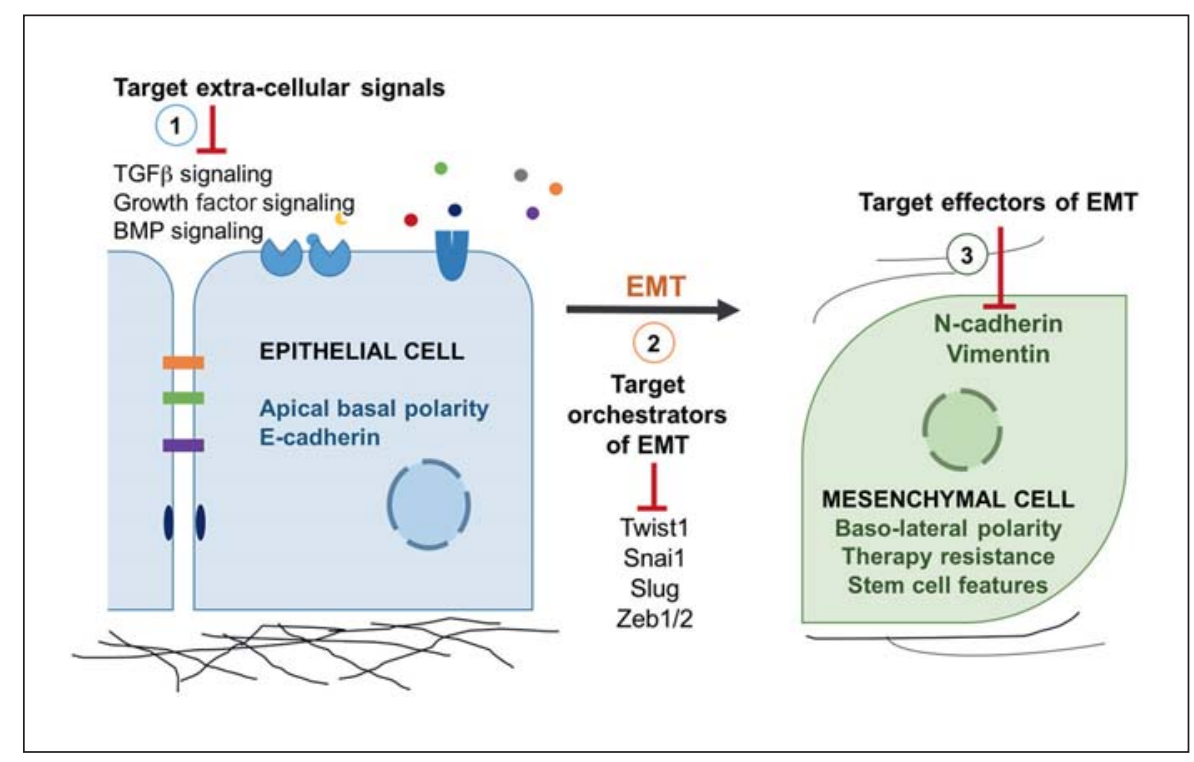

Compounds in clinical trials that may interfere with the EMT by blocking the TGF $\beta$ pathway include LY2157299, a TGF $\beta 1$ receptor inhibitor that specifically downregulates the phosphorylation of SMAD2. This compound has shown antitumor activity in animal models of breast, colon, lung, and hepatocellular carcinoma [Bueno et al., 2008; Rodon et al., 2013]. LY2157299 has also shown antitumor effects in patients with glioblastoma and hepatocellular carcinoma [Rodon et al., 2013]. This compound is currently being tested in the following 4 clinical trials: phase Ib/IIa in stages II-IV of unresectable pancreatic cancer of LY2157299 combined with gemcitabine versus gemcitabine plus placebo (NCT01373164); phase II in HCC patients with or without sorafenib (NCT01246986); a phase Ib/IIa study combining LY2157299 with standard temozolomide-based radiochemotherapy in patients with newly diagnosed malignant glioma (NCT01220271), and a phase II study of LY2157299 monohydrate monotherapy or LY2157299 monohydrate plus lomustine therapy compared to lomustine monotherapy in patients with recurrent glioblastoma (NCT01582269). In addition to inhibitors of TGF $\beta$, a human anti-TGF $\beta$ antibody (fresolimumab) has recently undergone a phase I clinical trial in patients with melanoma or renal cell carcinoma. It has demonstrated acceptable safety and toxicity and the maximum dose of 15 $\mathrm{mg} / \mathrm{kg}$ was established for phase II clinical trials. The antibody is being tested for antitumor activity in a phase II trial - fresolimumab and radiotherapy in metastatic breast cancer (NCT01401062).

\section{EGF Pathway}

EGF (epidermal growth factor) can induce EMT via signal transducer and activator of transcription 3 (STAT3) upregulation of the EMT transcription factor (TF), Twist1, in breast cancer cells. The EGFR kinase inhibitor AG1478 has been shown to block this activation in vitro [Lo et al., 2007]. Erlotinib, another EGFR tyrosine kinase inhibitor, is approved for the treatment of advanced NSCLC patients [Shepherd et al., 2005; Cappuzzo et al., 2010]. Importantly, the response to erlotinib is inversely correlated with lower levels of E-cadherin and higher levels of vimentin and Zeb1, suggesting that EMT may confer resistance to erlotinib [Witta et al., 2012].

\section{Axl-Gas6 Pathway}

The Axl receptor tyrosine kinase and its ligand, Gas6 (growth-arrest specific 6), have been implicated in maintaining the mesenchymal phenotype in some cell lines [Gjerdrum et al., 2010]. Rigel Pharmaceuticals Incorporated has a small molecular inhibitor of Axl kinase, BGB324 (formerly R428), which inhibits breast cancer metastasis alone and synergizes with cisplatin to inhibit liver metastases [Holland et al., 2010]. These studies indicate that the inhibition of some cell surface receptors may have roles beyond the initiation of EMT and may be used to target the mesenchymal cell type at later stages of the metastatic cascade. 


\section{Hypoxia}

Hypoxia is a well-characterized inducer of EMT in cancer cells [Marie-Egyptienne et al., 2013]. The ubiquitin C-terminal hydrolase-L1 (UCH-L1) is a deubiquitinating enzyme that hydrolyzes a peptide bond at the Cterminal glycine of ubiquitin. UCH-L1 deubiquitinated HIF-1 a promoted protein stability and resulted in the EMT and metastasis of different cancer cells. A specific small molecule inhibitor, LDN57444, targeting UCH-L1, significantly inhibited HIF-1 $\alpha$ activity in the presence of endogenous UCHL1 expression and suppressed EMT, reducing the incidence of distant tumor metastases [Jang et al., 2011; Goto et al., 2015]

\section{Extracellular Matrix}

Remodeling of the ECM and changes to cell interactions with the ECM are essential in the initiation and progression of EMT. As epithelial cells differentiate into mesenchymal cells they downregulate some epithelial integrins, but activate the expression of others; some of these newly expressed integrins have key roles in EMT progression [Yilmaz and Christofori, 2009]. Changes to the integrin repertoire during EMT correlate with the increased expression of proteases, such as the matrix metalloproteinases (MMP)2 and MMP9, thus enhancing ECM protein degradation and enabling invasion [Nisticò et al., 2012]. Some proteases and integrins can mediate invasion, such as $\alpha v \beta 6$, by activating the differentiation factor TGF $\beta$ that is stored in a latent form in the ECM [Sheppard, 2005]. This exposes the cells to increased TGF $\beta$ signaling, which promotes EMT and stimulates the expression of ECM proteins, such as collagens and fibronectin, enhancing the remodeling of the ECM into a matrix with a different composition and biophysical properties.

One limitation to targeting the ECM is that several of its components may work together to induce EMT and resistance may emerge quickly if only 1 of these pathways is impaired. Redundancy may be overcome by targeting multiple coacting intracellular signal transduction pathways. Furthermore, an additional strategy may be to target one of the crucial downstream signal transduction pathways that can activate an EMT transcription program. For example, there was compelling preclinical data for the use of MMP inhibitors for cancer therapy; however, most MMP inhibitors failed in clinical trials likely due to the complexity of the metastatic process [Sparano et al., 2004]. In addition to the MMP inhibitors MMP1 and MMP2, a microarray signature for lung-specific metastasis included the EGFR ligand, epiregulin, and COX2.
Administration of a cocktail of inhibitors of these proteins reduced the tumor volume and pulmonary metastases [Gupta et al., 2007].

\section{Targeting Orchestrators of EMT}

EMT is regulated by a core group of EMT-TFs, such as Snail1, Snail2 (Slug), a basic helix-loop-helix family (Twist1/2, E47, E2-2), and Zeb1/2 [Mikheeva et al., 2010; Kahlert et al., 2011; Lamouille et al., 2014; Teng and Li, 2014]. In addition, there is some indication that additional noncanonical transcription factors are also capable of inducing EMT in cancer cells, such as the T-box transcription factor Brachyury [Fernando et al., 2010], and thus may also serve as attractive therapeutic targets [Hamilton et al., 2013; Palena and Hamilton, 2015]. The function of these transcription factors in promoting and sustaining the neoplastic phenotype, cancer progression, and therapy resistance has been studied, and they present appealing targets to block EMT in tumors.

\section{Credentialing EMT-TFs as Cancer Therapeutic} Targets

There is ample evidence for the effectiveness of inhibiting EMT-TFs in blocking EMT in various normal and cancer cells. Inhibition of Twist 1 was first shown to reduce the frequency of lung metastases in the highly metastatic 4T1 mammary carcinoma cell line mouse model of breast cancer [Yang et al., 2004]. We and others have shown that Twist 1 downregulation can activate latent tumor suppressor programs of oncogene-induced senescence and apoptosis in oncogene-driven cancer cells in vitro and in vivo [Ansieau et al., 2008; Morel et al., 2012; Tran et al., 2012; Burns et al., 2013]. Twist1 inhibition also reduced the cell invasiveness in metastatic oral squamous cell carcinoma (OSCC) as shown in vitro and in vivo using an orthotropic model of OSCC [da Silva et al., 2014]. Twist 1 inhibition similarly reduces prostate cancer cell prometastatic phenotypes and alters sensitivity to both chemotherapy and hormonal therapy [Kwok et al., 2005; Shiota et al., 2010; Gajula et al., 2013; Shiota et al., 2013, 2014]. Many additional examples of credentialing the Snail family and Zeb1/2 EMT-TFs as cancer therapeutic targets are available [Nemeth and Kosz, 1989; Li et al., 2011; Tania et al., 2014].

EMT has also been shown to mediate resistance to traditional therapeutic agents and targeting EMT-TFs could increase cellular sensitivity to these agents. Renewed interest in this approach has come from a study using trans- 
genic mouse models of $\mathrm{Kras}^{G 12 D}$-induced pancreatic cancer [Zheng et al., 2015]. The group showed that deletion of the EMT-TFs Twist1 and Snail led to an increase in the expression of nucleoside transporters that contributed to enhanced sensitivity to gemcitabine treatment. Similarly, knockdown of Snail or Twist1 in lung carcinoma cell lines can restore chemosensitivity to cisplatin [Zhuo et al., 2008a, b]. Silencing Zeb1 in a panel of pancreatic cell lines increased their sensitivity to cancer therapeutics.

One caveat to this approach is the difficulty of identifying EMT-TFs that are active in tumor tissues. Expression of EMT-TFs can be regulated posttranscriptionally and/or posttranslationally [Zheng and Kang, 2014]; thus, their levels as determined by qRT-PCR or IHC may not correlate with activity. Furthermore, the spatial and temporal heterogeneity in expression of the various EMTTFs make them a challenging therapeutic target [Voulgari and Pintzas, 2009; Iwatsuki et al., 2010].

Targeting Signaling Pathways That Regulate EMT-TFs

Direct inhibition of transcription factors has been chemically challenging and studies reporting direct targeting of EMT-TFs are lacking. Another complimentary approach is to target regulators of EMT-TFs. We will summarize a few of these agents below. The cyclin-dependent kinase 4/6 inhibitor PD0332991 has been shown to downregulate Zeb1 expression in breast cancer cells [Arima et al., 2012]. The transcription factor STAT3 has critical roles in the regulation of EMT-TFs [Balanis et al., 2013; Davis et al., 2014a; Yuan et al., 2015] and several small molecule inhibitors of STAT3 have been developed, including Stattic [Schust et al., 2006], S3I-201 [Siddiquee et al., 2007], OPB-51602 [Ogura et al., 2015], and OPB31121 [Bendell et al., 2014]. Sulforaphane has been shown to downregulate Twist1 and vimentin, leading to a decrease in stem-like properties in pancreatic cancer cell lines [Srivastava et al., 2011]. Moscatilin (component of the orchid Dendrobrium loddigesii) suppresses the migration and metastasis of human breast cancer MDAMB-231 cells by targeting the Akt-Twist-dependent pathway [Pai et al., 2013]. Fucoidan (a brown seaweed polysaccharide) was also described to inhibit EMT in breast cancer cell lines such as $4 \mathrm{~T} 1$ and MDA-MB-231 through decreased Twist1, Snai1, and Snai2 expression [Hsu et al., 2013]. In head and neck cancer-derived sphere cells, quercetin (a major polyphenol and flavonoid, commonly detected in many fruits and vegetables) minimizes migration ability partially by decreasing the production of Twist, N-cadherin, and vimentin [Chang et al., 2013]. Thymoquinone (major active ingredient of the plant
Nigella sativa) increases Twist1 promoter methylation, resulting in Twist1 downregulation and the inhibition of migration, invasion, and upregulation of E-cadherin [Khan et al., 2015]. Imipramine blue promotes degradation of the EMT inducer Twist1 by enhancing FBXL14 (F-box and leucine-rich repeat protein 14) polyubiquitination-mediated destruction of Twist1 [Yang et al., 2016].

We also have our own data with the harmala alkaloids, which we isolated from a bioinformatic-chemical screen for Twist1 pathway inhibitors, demonstrating the posttranslational downregulation of the Twist1-E12/E47 heterodimeric complex in lung cancer cells in vitro and in vivo [Burns et al., unpubl. data]. Given our previous data credentialing Twist1 as a therapeutic target in various oncogene-driven lung cancer subtypes [Tran et al., 2012; Burns et al., 2013], we believe the development of this novel class of harmala Twist1 inhibitor compounds could have a significant clinical impact.

\section{Epigenetic Therapy Targeted against EMT-TFs}

Epigenetic changes are defined as heritable changes in gene expression that occur without changes in the DNA sequence and include DNA methylation and histone modification. Some consider RNA transcriptional regulation by micro-RNAs (miRNAs) to be another form of epigenetic regulation. DNA methylation is by far the beststudied epigenetic change in cancer cells. DNA methylation, the transfer of a methyl group to the carbon- 5 position of cytosines, occurs almost always within the context of cytosine-guanine $(\mathrm{CpG})$ dinucleotides in the promoter regions of genes. In cancer, $\mathrm{CpG}$ islands can become hypermethylated, contributing for example to the silencing of tumor suppressor genes like p53 [Baylin, 2005; SotoReyes and Recillas-Targa, 2010]. DNA methylation at $\mathrm{CpG}$ dinucleotides occurs through the action of DNA methyltransferase (DNMT) enzymes [Bird, 1986; Okano et al., 1998]. Noncoding microRNAs are also critical players in the neoplastic phenotype and have also been shown to have important regulatory roles in EMT [Hayes et al., 2014]. Noncoding miRNAs are small (19-25 nucleotides long), single-stranded RNAs that control gene expression by targeting mRNA transcripts, leading to their translational repression or degradation. Multiple miRNAs have been reported to suppress the EMT process [Gregory et al., 2008b]. The miR-200 family (miR-200a, miR-200b, miR-200c, miR-141, and miR-429) plays a critical regulatory role in EMT suppression, mainly through targeting ZEB1/2 [Koutsaki et al., 2014], and is downregulated in cancer cells during EMT [Bracken et al., 2008; Burk et al., 2008; Gregory et al., 2008a, b]. 
Interestingly, the CpG island near the miRNA-200c transcription start is unmethylated in epithelial cell lines, but is heavily methylated in transformed mesenchymal cells and invasive tumor cells [Davalos et al., 2012]. This epigenetic DNA methylation process can be inhibited through the use of 5-azacytidine or 5-aza-2'-deoxycytidine (5-aza), nucleoside analogs that bind to and inhibit DNMTs, leading to hypomethylation and increased gene expression [Juttermann et al., 1994; Bender et al., 1998; Kurkjian et al., 2008]. In fact, epigenetic therapy in the form of 5-aza treatment has been shown to upregulate the miRNA-200 family and reverse the EMT of mammary epithelial cells [Eades et al., 2011; Bi et al., 2015].

Histone lysine methylation has been extensively linked to both gene activation and gene repression events, depending on which lysine residues in the histones are methylated, and how many methyl groups are present [Lachner and Jenuwein, 2002]. Polycomb group protein complexes PRC1-4 play key roles in transcriptional silencing [Lachner and Jenuwein, 2002]. As shown by Herranz et al. [2008], Snail recruits the PRC2/EZH2 to the promoter of $\mathrm{CDH1}$, trimethylates Lys 27 on histone $\mathrm{H} 3$ (H3K27m3), and mediates the transcriptional repression of CDH1 [Cao et al., 2008; Herranz et al., 2008]. G9a (also known as KMT1C or EHMT2) is a major euchromatin methyltransferase responsible for $\mathrm{H} 3 \mathrm{~K} 9 \mathrm{me} 2$ levels [Tachibana et al., 2002]. Recent findings revealed that Snail binds with G9a and recruited G9a and DNMT to the $\mathrm{CDH} 1$ promoter, leading to DNA methylation. Knockdown of G9a restored E-cadherin expression by suppressing $\mathrm{H} 3 \mathrm{~K} 9 \mathrm{me} 2$ and blocking DNA methylation, and resulted in the suppression of tumor growth and lung colonization with in vivo models of breast cancer metastasis [Dong et al., 2012]. SET8 (also known as PR-Set7/9, SETD8, KMT5A) is a member of the SET domain-containing methyltransferase family specifically targeting H4K20 for monomethylation. Yang et al. [2012] demonstrated that the Twist transcription factor interacts with the monomethyltransferase SET8, which acts as a dual epigenetic modifier on the promoters of $\mathrm{E}$ - and N-cadherin to induce the expression of $\mathrm{N}$-cadherin and the repression of E-cadherin. Lysine-specific demethylase 1 (LSD1) was the first histone demethylase identified that catalyzes the removal of mono- and dimethylation marks on histone H3K4 and H3K9 [Shi et al., 2004; Metzger et al., 2005]. As shown by Lin et al. [2010], Snail recruits the histone demethylase LSD1 (KDM1A, AOF2) to dimethylate Lys4 on histone $\mathrm{H} 3(\mathrm{H} 3 \mathrm{~K} 4 \mathrm{~m} 2)$ and mediates the transcriptional repression of Snail target genes, such as $\mathrm{CDH} 1$.

Agents That Target EMT
Drugs targeting histone methyltransferases and demethylases are still in their infancy. Several compounds have been developed recently, such as the G9a inhibitors UNC0638 and BRD4770 and the EZH2 inhibitor EPZ005687. Those compounds have already demonstrated antitumor activity on breast cancer cells, pancreatic cancer cells, and lymphoma cells in vitro [Vedadi et al., 2011; Knutson et al., 2012; Wagner and Jung, 2012; Yuan et al., 2012]. However, their effects on EMT and migration have yet to be explored.

\section{Targeting Glycosylation Pathways That Regulate}

EMT-TFs

Glycosylation is a form of cotranslational and posttranslational modification that plays important roles during embryogenesis [Haltiwanger and Lowe, 2004]. Aberrant glycosylation has also been associated with the malignant transformation of cells [Kim and Varki, 1997] and has been discovered in many cancers, including melanoma [Pochec et al., 2013], colon [Holst et al., 2015], breast [Guo and Abbott, 2015], lung [Lemjabbar-Alaoui et al., 2015], liver [Mehta et al., 2015], and prostate cancers [Drake et al., 2015]. Two major forms of protein glycosylation are $\mathrm{N}$-glycosylation and $\mathrm{O}$-glycosylation. We will focus on the $\mathrm{O}$-glycosylation known as O-linked $\beta$-N-acetylglucosamine (O-GlcNAc), which is conserved among multicellular eukaryotes. This modification regulates diverse cellular processes, including gene expression [Gambetta et al., 2009; Hanover et al., 2012], stress response [Zachara et al., 2004; Ohn et al., 2008], and circadian rhythm [Kim et al., 2012; Li et al., 2013]. The OGlcNAcylation level was demonstrated to be globally elevated and correlated with aggressiveness in a number of malignancies, including breast [Gu et al., 2010; Krzeslak et al., 2012; Champattanachai et al., 2013], prostate [Gu et al., 2014; Kamigaito et al., 2014], lung [Mi et al., 2011], pancreas [Ma et al., 2013], liver [Zhu et al., 2012], and colon cancers [Mi et al., 2011; Yehezkel et al., 2012; Phueaouan et al., 2013]. While the O-GlcNAcylation modification is analogous to ATP phosphorylation in many ways, unlike the hundreds of kinases, protein $\mathrm{O}$ GlcNAcylation is regulated by only 2 enzymes: OGlcNAc transferase (OGT) adds O-GlcNAc on proteins [Haltiwanger et al., 1990; Lubas et al., 1997], and OGlcNAcase removes O-GlcNAc [Gao et al., 2001]. These 2 enzymes act together to dynamically modulate the levels of O-GlcNAc on proteins within cells. The addition of O-GlcNAc generally stabilizes modified proteins and prevents them from degradation by the ubiquitin-proteasome system [Yang et al., 2006; Park et al., 2010; Li et al.,

Cells Tissues Organs 2017;203:114-127 119 
2013; Ruan et al., 2013; Olivier-Van Stichelen et al., 2014]. One important class of proteins heavily OGlcNAcylated are TFs. Early O-GlcNAc proteome analyses suggested over $25 \%$ of known O-GlcNAcylated proteins were in fact transcription factors [Love and Hanover, 2005]. For the majority of these TFs, OGlcNAcylation serves as a direct or indirect competitor of key phosphorylation sites. Particularly relevant to EMT is the O-GlcNAcylation of Snai1. It is known that Snail activity is regulated by phosphorylation. Upon serial phosphorylation by CK1 and glycogen synthase kinase (GSK)-3 $\beta$, Snail is primed for nuclear export, $\beta$-TrCP ubiquitination, and subsequent proteosomal degradation [Zhou et al., 2004; Xu et al., 2010]. However, in hyperglycemic conditions, Snail is O-GlcNAcylated to prevent GSK-3 $\beta$ phosphorylation, thus leading to Snail stabilization, E-cadherin repression, and cancer cells to undergo EMT-mediated migration [Park et al., 2010]. Other than Snai1, O-GlcNAcylation occurs on a number of transcription factors generally relevant to EMT including c-Myc [Chou et al., 1995], $\beta$-catenin [Olivier-Van Stichelen et al., 2014], and NF- $\mathrm{B}$ [Yang et al., 2008; Allison et al., 2012].

Several OGT inhibitors have so far been developed. An OGT inhibitor identified in a screen of a small molecule library reduces breast cancer cell hyper-O-GlcNAcylation and blocks anchorage-independent growth [Chou et al., 1995; Caldwell et al., 2010]. However, the potency of the inhibitor is relatively low. 5-thioglucosamine (5SGlcNAc) and its per-O-acetylated analog Ac5SGlcNAc have been developed as alternative OGT inhibitors [Gloster et al., 2011]. Ac-5SGlcNAc can be converted into UDP-5SGlcNAc via the GlcNAc salvage pathway, thereby competing with UDP-GlcNAc and inhibiting O-GlcNAcylation [Gloster et al., 2011]. It has been shown that Ac-5SGlcNAc is able to reduce pancreatic cancer cell hyper-O-GlcNAcylation and inhibit cell growth in vitro [Ma et al., 2013]. However, the effects of these compounds on EMT were not reported in either of these studies. Other OGT inhibitors, such as ST045849 and Alloxan, have been shown to inhibit migration and proliferation in mouse embryonic stem cells and retinal pericytes, respectively [Gurel et al., 2013; Jeon et al., 2013].

The monosaccharide GlcNAc is the product of the hexosamine biosynthesis pathway which produces UDPGlcNAc [Hanover et al., 2012]. Therefore, a second reasonable target is to inhibit GFPT2, the rate-limiting enzyme in the hexosamine biosynthesis pathway. Currently, DON and azaserine are commonly used GFPT2 inhibitors [James et al., 2002]. Both compounds demonstrated potent inhibition of cell viability [Catane et al., 1979; Olsen et al., 2015]. DON also exhibit as much as 10 times more cytotoxicity upon 2 types of murine leukemia cell as compared to normal embryonic fibroblasts [Rosenfeld and Roberts, 1981]. Systemic administration of DON in the VM-M3 murine tumor model also led to a profound decrease in tumor proliferation and inhibition of visceral metastases [Shelton et al., 2010]. However, off-target effects are likely with DON as it can inhibit a number of glutamine utilizing enzymes [Thangavelu et al., 2014].

\section{Immunotherapy Approaches to Target EMT-TFs}

When cancer cells undergo EMT, there are profound morphological changes dictated by accompanying gene expression and protein changes, many of which are silenced following embryogenesis. It is possible that the immune system may be able recognize and act on these neoplastic EMT changes. Ardiani et al. [2014] demonstrated that in principal this concept is feasible. They expressed Twist 1 in heat-killed yeast and immunized tumor-bearing mice with this recombinant yeast. After vaccination, they confirmed that both CD4+ and CD8+ Twist-specific T-cell responses were induced. Surprisingly, not only did the primary tumor grow much slower in the recombinant Twist1-vaccinated mice, the number of clonogenic metastatic cells was also significantly decreased after Twist 1 vaccination. As remarked on previously, the noncanonical EMT-TF Brachyury has also served as an attractive therapeutic target and was used in a similar heatkilled yeast vaccination platform (designated as GI-6301), demonstrating similar immunologic and in vivo tumor responses [Hamilton et al., 2013; Palena and Hamilton, 2015]. Based on these results, a phase I clinical trial of GI6301 was initiated and accrued recently in patients with advanced tumors (NCT01519817). A follow-up phase II trial in chordoma patients in combination with standard of care radiotherapy is ongoing (NCT02383498). Preclinical results from these seminal studies provide evidence that EMT-TFs can be processed in the cytoplasm and presented on the cell surface by either MHC class I or MHC class II molecules, offering a novel strategy to target EMTTFs in cancer. These EMT-TF vaccination strategies should be explored further in combination with traditional cancer therapies such as chemotherapy and radiation, but also in combination with other complimentary immunotherapies. 


\section{Targeting Effectors of EMT}

EMT is frequently characterized by acquisition of a plethora of mesenchymal cell markers such as vimentin, $\mathrm{N}$-cadherin, and fibronectin, and loss of epithelial markers such as E-cadherin and cytokeratins. These changes are associated with increased cell mobility and invasion, and are frequently found in circulating tumor cells and cells from metastatic lesions [Bednarz-Knoll et al., 2012; Yu et al., 2013]. Targeting these proteins may benefit patients with more advanced disease by eliminating existing metastatic cells. In addition, this same approach may target cancers of mesenchymal origins such as sarcomas.

\section{E-Cadherin}

It has been shown that transfection of E-cadherin in highly mesenchymal and invasive cells can revert poorly differentiated carcinoma cells into a more differentiated state with a minimal invasive phenotype [Luo et al., 1999; Wong and Gumbiner, 2003; Witta et al., 2006]. E-cadherin has been established as a tumor suppressor in many cancers, including breast cancer [Berx and van Roy, 2001], HCC [Zhai et al., 2008], melanoma [Molina-Ortiz et al., 2009], and esophageal cancer [Ling et al., 2011]. In contrast, E-cadherin is upregulated in ovarian cancer cells that metastasize to the peritoneum and omentum [Köbel et al., 2011]. Additionally, several studies suggest that E-cadherin may promote tumor progression in various epithelial cancers, such as ovarian, breast, or brain cancer [Rodriguez et al., 2012]. Thus, targeting E-cadherin for therapeutic gain is challenging, owing to its multifaceted and context-specific role in carcinogenesis. Despite these challenges, Gupta et al. [2009] used a highthroughput screening approach to identify compounds that may selectively target E-cadherin-negative breast epithelial cells as compared to E-cadherin-positive cells in mouse models. Salinomycin, a potassium ionophore, was identified as having significant toxicity against mesenchymal-type breast cancer cells (independent of the mechanism used to induce EMT in these cells). This is in contrast to treatment with paclitaxel, which significantly increased the enrichment for EMT and stem cell markers in breast cancer cell lines surviving chemotherapy.

Another orthogonal strategy that focuses on E-cadherin is targeting the epigenetic regulatory machinery, as described above. $\mathrm{CDH} 1$ has a large $\mathrm{CpG}$ island in the 5 '-proximal promoter region, which shows aberrant DNA methylation in many different human cancers and correlates with reduced E-cadherin protein expressions [Graff et al., 1995; Yoshiura et al., 1995]. It was reported that hypermethylation at the $\mathrm{CDH} 1$ promoter inversely correlated with the expression of E-cadherin in 11 different cancer cell lines, and treatment with 5 -aza caused the reexpression of E-cadherin, reversion of spindle-shaped cells to cells with epithelial morphology, and reduced metastasis in these cancer cells [Yoshiura et al., 1995; Nam et al., 2004]. In an in vivo model of breast cancer using the cell-line MDA-MB-435S, 5-aza was able to restore E-cadherin expression and suppress metastasis formation as well as primary growth, possibly through E-cadherin upregulation [Nam et al., 2004].

Histones, the major components of chromatin, can undergo multiple posttranslational modifications, such as acetylation by histone acetyltransferases and deacetylation by histone deacetylases (HDACs), resulting in chromatin that is permissive for transcriptional activation and repression, respectively [Struhl, 1998; Archer and Hodin, 1999]. Histone deacetylation can be inhibited by HDAC inhibitors, which promotes accumulation of the acetylated form of histone proteins, leading to less condensed chromatin and the reexpression of silenced genes. HDAC inhibitors have been shown in preclinical studies to selectively target cancer cells by inducing apoptosis, cell cycle arrest, suppression of tumor angiogenesis, and metastasis and invasion at least partially through upregulating E-cadherin [Shaker et al., 2004]. The first HDAC inhibitor identified was butyrate, which was shown to induce cell-cycle arrest and to increase cell-cell adhesion in breast cancer cells. Interestingly, this effect has been shown to be reversible upon the addition of E-cadherin antibodies [Kondo et al., 1998]. Butyrate was also found to upregulate E-cadherin expression in many other cancer cells, including colon cancer, liver cancer, and endometrial carcinoma cells [Barshishat et al., 2000; Masuda et al., 2000; Takai et al., 2004]. Other HDAC inhibitors, such as Trichostatin A and SAHA (suberoylanilide hydroxamic acid), are also capable of stimulating E-cadherin expression in endometrial carcinoma cell lines [Takai et al., 2004]. Sodium butyrate is currently being tested in phase I and II trials. SAHA, structurally similar to trichostatin A, was approved by the US FDA in 2006 for the treatment of advanced and refractory primary cutaneous T-cell lymphoma, and is marketed as vorinostat $\left(\right.$ Zolinza $\left.^{\circledR}\right)$ [Mann et al., 2007; Ma et al., 2009].

\section{$N$-Cadherin}

Inhibition of $\mathrm{N}$-cadherin has been proposed in several studies. Blocking N-cadherin using the peptide ADH-1 was shown to prevent tumor progression in a mouse model of pancreatic cancer [Shintani et al., 2008]. Targeting N-cadherin using a monoclonal antibody approach has also been 
shown to inhibit prostate cancer cell invasion and reduce metastasis formation [Tanaka et al., 2010]. In multiple myeloma cells, the $\mathrm{N}$-cadherin neutralizing antibody impeded the proliferation of cancer cells [Sadler et al., 2013]. Quercetin, a natural polyphenol found in vegetables, reduced the migration ability of head and neck cancer cells partially due to the decreased production of $\mathrm{N}$-cadherin, vimentin, and the EMT-TF, Twist1 [Chang et al., 2013].

\section{Vimentin}

Another marker of EMT, and thus a potentially important effector, is vimentin [Satelli and Li, 2011]. There are only a few reports showing the direct inhibition of vimentin using bioactive compounds. Withaferin-A is a compound extracted from Withania somnifera that can promote the degradation of vimentin in breast and lung cancer cell lines, leading to the inhibition of cell migration and invasion and apoptosis at higher concentrations and inhibition of metastasis formation in in vivo xenograft studies [Lahat et al., 2010]. Two compounds, silibium and flavonolignan, were shown to inhibit the invasion, motility, and migration of cancer cells through the downregulation of vimentin in cancer cell lines and mouse models [Singh et al., 2008; Wu et al., 2009].

Statins, the cholesterol-reducing drugs, attenuate the growth of mesenchymal-like cancer cells that show an increased expression of vimentin. Exogenous expression of cell surface E-cadherin converts statin-sensitive cells to a partially resistant state, implying that statin resistance is in part dependent on the tumor cells attaining an epithelial phenotype. As metastasizing epithelial tumor cells may undergo EMT during the metastatic cascade, statin therapy may represent an effective approach to targeting the cells most likely to disseminate [Warita et al., 2014].

\section{HoxA9}

We have demonstrated previously that Twist 1 activates the transcription of HoxA9, which contributes to the induction of a Twist1-dependent metastatic phenotype in prostate cancer cells [Gajula et al., 2013]. Twist1 is canonically known as a transcription factor, but recent data suggest an epigenetic role for Twist1 in gene regulation $[\mathrm{Wu}$ et al., 2011; Yang et al., 2012]. During embryogenesis, the histone methyltransferase complex MLL-WDR5 and the long noncoding RNA HOTTIP regulate the expression of the HoxA cluster of genes by $\mathrm{H} 3 \mathrm{~K} 4$ chromatin methylation [Wang et al., 2011]. Interestingly, prostate cancer whole exome sequencing has shown frequent mutations in MLL2 [Grasso et al., 2012]. Our unpublished data have demonstrated that Twist1 and HoxA9 are co-overex- pressed in the developing mouse prostate and human prostate cancer samples, and that Twist 1 forms a complex with the MLL-WDR5-HOTTIP (MWH) methyltransferase complex and is found to be co-overexpressed in prostate cancers, particularly in the metastases. We also demonstrated that this Twist1-MWH complex activates HoxA9 expression by $\mathrm{H} 3 \mathrm{~K} 4 \mathrm{me} 3$ chromatin modification of the HoxA9 promoter region, and that the MWH complex is required for full Twist1-induced prometastatic behaviors in prostate cancer. Thus, our data suggest that reactivation of a latent developmental program involving a Twist1-MWH complex drives the expression of HoxA9, mediating prostate cancer metastasis. We have also shown that Twist1-induced prometastatic behaviors in prostate cancer cells can be pharmacologically subdued by targeting HoxA9 indirectly with UNC0646, a small-molecule inhibitor of the methyltransferase G9a [Lehnertz et al., 2014], or directly with a peptide that disrupts Hoxa9 function [Ando et al., 2014; [Tran et al., unpubl. data].

\section{Conclusion}

Our understanding of the consequences of the EMT program in cancer suggests a broad effect on the neoplastic phenotype involving early tumorigenesis, tumor progression, and treatment resistance. Thus, targeting epithelial plasticity programs such as EMT represents a promising strategy to treat the neoplastic phenotype along the full spectrum of cancers. With increased knowledge of EMT signaling and regulation, many specific compounds have been developed that may target EMT, many of which we have discussed in this review. However, the heterogeneity of tumors and the dynamic nature of epithelial plasticity in cancer cells make it likely that targeting only 1 EMT-related process (Fig. 1, 1-3) will be unsuccessful or only transiently successful. Thus, we envision that systematically targeting EMT regulatory networks provides the best option for success. With the development of more specific pathway inhibitors, new pathways to target, such as glycosylation, new combinations of agents, and novel strategies that involve the immune system, we expect to see significant advances in targeting epithelial plasticity programs for cancer treatment.

\section{Acknowledgements}

R. Malek was funded by the Prostate Cancer Foundation. H. Wang was funded by Uniting Against Lung Cancer. K. Taparra was funded by the NIH (F31CA189588). P.T. Tran was funded by 
the Motta and Nesbitt families, the DoD (W81XWH-11-1-0272), a Kimmel Translational Science Award (SKF-13-021), an ACS Scholar Award (122688-RSG-12-196-01-TBG), the NIH (R01CA166348), the American Lung Association (LCD-339465), and a Movember-PCF Challenge Award.

\section{Disclosure Statement}

The authors declare that they have no competing interests.

\section{References}

Allison, D.F., J.J. Wamsley, M. Kumar, D. Li, L.G. Gray, G.W. Hart, D.R. Jones, M.W. Mayo (2012) Modification of RelA by O-linked $N$ acetylglucosamine links glucose metabolism to NF- $\kappa B$ acetylation and transcription. Proc Natl Acad Sci USA 109: 16888-16893.

Ando, H., A. Natsume, T. Senga, R. Watanabe, I. Ito, M. Ohno, K. Iwami, F. Ohka, K. Motomura, S. Kinjo, M. Ito, K. Saito, R. Morgan, T. Wakabayashi (2014) Peptide-based inhibition of the HOXA9/PBX interaction retards the growth of human meningioma. Cancer Chemother Pharmacol 73: 53-60.

Ansieau, S., J. Bastid, A. Doreau, A.P. Morel, B.P. Bouchet, C. Thomas, F. Fauvet, I. Puisieux, C. Doglioni, S. Piccinin, et al. (2008) Induction of EMT by twist proteins as a collateral effect of tumor-promoting inactivation of premature senescence. Cancer Cell 14: 79-89.

Archer, S.Y., R.A. Hodin (1999) Histone acetylation and cancer. Curr Opin Genet Dev 9:171174.

Ardiani, A., S.R. Gameiro, C. Palena, D.H. Hamilton, A. Kwilas, T.H. King, J. Schlom, J.W. Hodge (2014) Vaccine-mediated immunotherapy directed against a transcription factor driving the metastatic process. Cancer Res 74: 1945-1957.

Arima, Y., H. Hayashi, M. Sasaki, M. Hosonaga, T.M. Goto, T. Chiyoda, S. Kuninaka, T. Shibata, H. Ohata, H. Nakagama, et al. (2012) Induction of ZEB proteins by inactivation of RB protein is key determinant of mesenchymal phenotype of breast cancer. J Biol Chem 287: 7896-7906.

Balanis, N., M.K. Wendt, B.J. Schiemann, Z. Wang, W.P. Schiemann, C.R. Carlin (2013) Epithelial to mesenchymal transition promotes breast cancer progression via a fibronectin-dependent STAT3 signaling pathway. J Biol Chem 288: 17954-17967.

Barshishat, M., S. Polak-Charcon, B. Schwartz (2000) Butyrate regulates E-cadherin transcription, isoform expression and intracellular position in colon cancer cells. Br J Cancer 82: 195-203.

Baylin, S.B. (2005) DNA methylation and gene silencing in cancer. Nat Clin Pract Oncol 2(suppl 1): S4-S11.

Bednarz-Knoll, N., C. Alix-Panabières, K. Pantel (2012) Plasticity of disseminating cancer cells in patients with epithelial malignancies. Cancer Metastasis Rev 31: 673-687.

Bendell, J.C., D.S. Hong, H.A. Burris, A. Naing, S.F. Jones, G. Falchook, P. Bricmont, A.
Elekes, E.P. Rock, R. Kurzrock (2014) Phase 1, open-label, dose-escalation, and pharmacokinetic study of STAT3 inhibitor OPB31121 in subjects with advanced solid tumors. Cancer Chemother Pharmacol 74: 125-130.

Bender, C.M., M.M. Pao, P.A. Jones (1998) Inhibition of DNA methylation by 5 -aza-2'deoxycytidine suppresses the growth of human tumor cell lines. Cancer Res 58: 95-101.

Berx, G., F. van Roy (2001) The E-cadherin/ catenin complex: an important gatekeeper in breast cancer tumorigenesis and malignant progression. Breast Cancer Res 3: 289-293.

Bi, C., T.H. Chung, G. Huang, J. Zhou, J. Yan, G.J. Ahmann, R. Fonseca, W.J. Chng (2015) Genome-wide pharmacologic unmasking identifies tumor suppressive microRNAs in multiple myeloma. Oncotarget 6: 26508-26518.

Bird, A.P. (1986) CpG-rich islands and the function of DNA methylation. Nature 321: 209213.

Bracken, C.P., P.A. Gregory, N. Kolesnikoff, A.G. Bert, J. Wang, M.F. Shannon, G.J. Goodall (2008) A double-negative feedback loop between ZEB1-SIP1 and the microRNA-200 family regulates epithelial-mesenchymal transition. Cancer Res 68: 7846-7854.

Bueno, L., D.P. de Alwis, C. Pitou, J. Yingling, M. Lahn, S. Glatt, I.F. Trocóniz (2008) Semimechanistic modelling of the tumour growth inhibitory effects of LY2157299, a new type I receptor TGF- $\beta$ kinase antagonist, in mice. Eur J Cancer 44: 142-150.

Burk, U., J. Schubert, U. Wellner, O. Schmalhofer, E. Vincan, S. Spaderna, T. Brabletz (2008) A reciprocal repression between ZEB1 and members of the miR-200 family promotes EMT and invasion in cancer cells. EMBO Rep 9: 582-589.

Burns, T.F., I. Dobromilskaya, S.C. Murphy, R.P. Gajula, S. Thiyagarajan, S.N.H. Chatley, K. Aziz, Y.-J. Cho, P.T. Tran, C.M. Rudin (2013) Inhibition of TWIST1 leads to activation of oncogene-induced senescence in oncogenedriven non-small cell lung cancer. Mol Cancer Res 11: 329-338.

Caldwell, S.A., S.R. Jackson, K.S. Shahriari, T.P. Lynch, G. Sethi, S. Walker, K. Vosseller, M.J. Reginato (2010) Nutrient sensor O-GlcNAc transferase regulates breast cancer tumorigenesis through targeting of the oncogenic transcription factor FoxM1. Oncogene 29: 2831-2842.

Cao, Q., J. Yu, S.M. Dhanasekaran, J.H. Kim, R.S. Mani, S.A. Tomlins, R. Mehra, B. Laxman, X.
Cao, C.G. Kleer, et al. (2008) Repression of Ecadherin by the polycomb group protein EZH2 in cancer. Oncogene 27: 7274-7284.

Cappuzzo, F., T. Ciuleanu, L. Stelmakh, S. Cicenas, A. Szczésna, E. Juhász, E. Esteban, O. Molinier, W. Brugger, I. Melezínek, et al. (2010) Erlotinib as maintenance treatment in advanced non-small-cell lung cancer: a multicentre, randomised, placebo-controlled phase 3 study. Lancet Oncol 11: 521-529.

Catane, R., D.D. Von Hoff, D.L. Glaubiger, F.M. Muggia (1979) Azaserine, DON, and azotomycin: three diazo analogs of L-glutamine with clinical antitumor activity. Cancer Treat Rep 63: 1033-1038.

Champattanachai, V., P. Netsirisawan, P. Chaiyawat, T. Phueaouan, R. Charoenwattanasatien, D. Chokchaichamnankit, P. Punyarit, C. Srisomsap, J. Svasti (2013) Proteomic analysis and abrogated expression of O-GlcNAcylated proteins associated with primary breast cancer. Proteomics 13: 2088-2099.

Chang, W.W., F.W. Hu, C.C. Yu, H.H. Wang, H.P. Feng, C. Lan, L.L. Tsai, Y.C. Chang (2013) Quercetin in elimination of tumor initiating stem-like and mesenchymal transformation property in head and neck cancer. Head Neck 35: 413-419.

Chou, T.Y., C.V. Dang, G.W. Hart (1995) Glycosylation of the c-Myc transactivation domain. Proc Natl Acad Sci USA 92: 4417-4421.

Chua, K.-N., W.-J. Sim, V. Racine, S.-Y. Lee, B.C. Goh, J.P. Thiery (2012) A cell-based small molecule screening method for identifying inhibitors of epithelial-mesenchymal transition in carcinoma. PLoS One 7: e33183.

da Silva, S.D., M.A. Alaoui-Jamali, F.A. Soares, D.M. Carraro, H.P. Brentani, M. Hier, S.R. Rogatto, L.P. Kowalski (2014) TWIST1 is a molecular marker for a poor prognosis in oral cancer and represents a potential therapeutic target. Cancer 120: 352-362.

Davalos, V., C. Moutinho, A. Villanueva, R. Boque, P. Silva, F. Carneiro, M. Esteller (2012) Dynamic epigenetic regulation of the microRNA-200 family mediates epithelial and mesenchymal transitions in human tumorigenesis. Oncogene 31: 2062-2074.

Davis, F.M., I. Azimi, R.A. Faville, A.A. Peters, K. Jalink, J.W. Putney, G.J. Goodhill, E.W. Thompson, S.J. Roberts-Thomson, G.R. Monteith (2014a) Induction of epithelialmesenchymal transition (EMT) in breast cancer cells is calcium signal dependent. Oncogene 33: 2307-2316. 
Davis, F.M., T.A. Stewart, E.W. Thompson, G.R. Monteith (2014b) Targeting EMT in cancer: opportunities for pharmacological intervention. Trends Pharmacol Sci 35: 479-488.

Dong, C., Y. Wu, J. Yao, Y. Wang, Y. Yu, P.G. Rychahou, B.M. Evers, B.P. Zhou (2012) G9a interacts with Snail and is critical for Snailmediated E-cadherin repression in human breast cancer. J Clin Invest 122: 1469-1486.

Drake, R.R., E.E. Jones, T.W. Powers, J.O. Nyalwidhe (2015) Altered glycosylation in prostate cancer. Adv Cancer Res 126: 345-382.

Eades, G., Y. Yao, M. Yang, Y. Zhang, S. Chumsri, Q.Zhou (2011) miR-200a regulates SIRT1 expression and epithelial to mesenchymal transition (EMT)-like transformation in mammary epithelial cells. J Biol Chem 286: 2599226002.

Fernando, R.I., M. Litzinger, P. Trono, D.H. Hamilton, J. Schlom, C. Palena (2010) The Tbox transcription factor Brachyury promotes epithelial-mesenchymal transition in human tumor cells. J Clin Invest 120: 533-544.

Gajula, R.P., S.T. Chettiar, R.D. Williams, S. Thiyagarajan, Y. Kato, K. Aziz, R. Wang, N. Gandhi, A.T. Wild, F. Vesuna, et al. (2013) The twist box domain is required for Twist1-induced prostate cancer metastasis. Mol Cancer Res 11: 1387-1400.

Gambetta, M.C., K. Oktaba, J. Muller (2009) Essential role of the glycosyltransferase sxc/Ogt in polycomb repression. Science 325: 93-96.

Gao, Y., L. Wells, F.I. Comer, G.J. Parker, G.W. Hart (2001) Dynamic O-glycosylation of nuclear and cytosolic proteins: cloning and characterization of a neutral, cytosolic $\beta-\mathrm{N}$ acetylglucosaminidase from human brain. J Biol Chem 276: 9838-9845.

Gjerdrum, C., C. Tiron, T. Høiby, I. Stefansson, H. Haugen, T. Sandal, K. Collett, S. Li, E. McCormack, B.T. Gjertsen, et al. (2010) Axl is an essential epithelial-to-mesenchymal transition-induced regulator of breast cancer metastasis and patient survival. Proc Natl Acad Sci USA 107: 1124-1129.

Gloster, T.M., W.F. Zandberg, J.E. Heinonen, D.L. Shen, L. Deng, D.J. Vocadlo (2011) Hijacking a biosynthetic pathway yields a glycosyltransferase inhibitor within cells. Nat Chem Biol 7: 174-181.

Goto, Y., L. Zeng, C.J. Yeom, Y. Zhu, A. Morinibu, K. Shinomiya, M. Kobayashi, K. Hirota, S. Itasaka, M. Yoshimura, et al. (2015) UCHL1 provides diagnostic and antimetastatic strategies due to its deubiquitinating effect on HIF1a. Nat Commun 6: 6153.

Graff, J.R., J.G. Herman, R.G. Lapidus, H. Chopra, R. Xu, D.F. Jarrard, W.B. Isaacs, P.M. Pitha, N.E. Davidson, S.B. Baylin (1995) Ecadherin expression is silenced by DNA hypermethylation in human breast and prostate carcinomas. Cancer Res 55: 5195-5199.

Grasso, C.S., Y.M. Wu, D.R. Robinson, X. Cao, S.M. Dhanasekaran, A.P. Khan, M.J. Quist, X. Jing, R.J. Lonigro, J.C. Brenner, et al. (2012) The mutational landscape of lethal castration-resistant prostate cancer. Nature 487: 239-243.
Gregory, P.A., A.G. Bert, E.L. Paterson, S.C. Barry, A. Tsykin, G. Farshid, M.A. Vadas, Y. Khew-Goodall, G.J. Goodall (2008a) The miR-200 family and miR-205 regulate epithelial to mesenchymal transition by targeting ZEB1 and SIP1. Nat Cell Biol 10: 593-601.

Gregory, P.A., C.P. Bracken, A.G. Bert, G.J. Goodall (2008b) MicroRNAs as regulators of epithelial-mesenchymal transition. Cell Cycle 7: 3112-3118.

Gu, Y., J. Gao, C. Han, X. Zhang, H. Liu, L. Ma, X. Sun, W. Yu (2014) O-GlcNAcylation is increased in prostate cancer tissues and enhances malignancy of prostate cancer cells. Mol Med Rep 10: 897-904.

Gu, Y., W. Mi, Y. Ge, H. Liu, Q. Fan, C. Han, J. Yang, F. Han, X. Lu, W. Yu (2010) GlcNAcylation plays an essential role in breast cancer metastasis. Cancer Res 70: 6344-6351.

Guo, H., K.L. Abbott (2015) Functional impact of tumor-specific N-linked glycan changes in breast and ovarian cancers. Adv Cancer Res 126: $281-303$

Gupta, G.P., D.X. Nguyen, A.C. Chiang, P.D. Bos, J.Y. Kim, C. Nadal, R.R. Gomis, K. ManovaTodorova, J. Massagué (2007) Mediators of vascular remodelling co-opted for sequential steps in lung metastasis. Nature 446: 765-770.

Gupta, P.B., T.T. Onder, G. Jiang, K. Tao, C. Kuperwasser, R.A. Weinberg, E.S. Lander (2009) Identification of selective inhibitors of cancer stem cells by high-throughput screening. Cell 138: 645-659.

Gurel, Z., K.M. Sieg, K.D. Shallow, C.M. Sorenson, N. Sheibani (2013) Retinal O-linked Nacetylglucosamine protein modifications: implications for postnatal retinal vascularization and the pathogenesis of diabetic retinopathy. Mol Vis 19: 1047-1059.

Halder, S.K., R.D. Beauchamp, P.K. Datta (2005) A specific inhibitor of TGF- $\beta$ receptor kinase, SB-431542, as a potent antitumor agent for human cancers. Neoplasia 7: 509-521.

Haltiwanger, R.S., G.D. Holt, G.W. Hart (1990) Enzymatic addition of $O$-GlcNAc to nuclear and cytoplasmic proteins: identification of a uridine diphospho- $N$-acetylglucosamine:peptide $\beta-N$ acetylglucosaminyltransferase. J Biol Chem 265: 2563-2568.

Haltiwanger, R.S., J.B. Lowe (2004) Role of glycosylation in development. Ann Rev Biochem 73: 491-537.

Hamilton, D.H., M.T. Litzinger, A. Jales, B. Huang, R.I. Fernando, J.W. Hodge, A. Ardiani, D. Apelian, J. Schlom, C. Palena (2013) Immunological targeting of tumor cells undergoing an epithelial-mesenchymal transition via a recombinant brachyury-yeast vaccine. Oncotarget 4: 1777-1790.

Hanover, J.A., M.W. Krause, D.C. Love (2012) Bittersweet memories: linking metabolism to epigenetics through O-GlcNAcylation. Nat Rev Mol Cell Biol 13: 312-321.

Hayes, J., P.P. Peruzzi, S. Lawler (2014) MicroRNAs in cancer: biomarkers, functions and therapy. Trends Mol Med 20: 460-469.
Herranz, N., D. Pasini, V.M. Diaz, C. Franci, A. Gutierrez, N. Dave, M. Escriva, I. HernandezMunoz, L. Di Croce, K. Helin, et al. (2008) Polycomb complex 2 is required for E-cadherin repression by the Snaill transcription factor. Mol Cell Biol 28: 4772-4781.

Holland, S.J., A. Pan, C. Franci, Y. Hu, B. Chang, W. Li, M. Duan, A. Torneros, J. Yu, T.J. Heckrodt, et al. (2010) R428, a selective small molecule inhibitor of Axl kinase, blocks tumor spread and prolongs survival in models of metastatic breast cancer. Cancer Res 70: 1544-1554.

Holst, S., M. Wuhrer, Y. Rombouts (2015) Glycosylation characteristics of colorectal cancer. Adv Cancer Res 126: 203-256.

Hsu, H.-Y., T.-Y. Lin, P.-A. Hwang, L.-M. Tseng, R.-H. Chen, S.-M. Tsao, J. Hsu (2013) Fucoidan induces changes in the epithelial to mesenchymal transition and decreases metastasis by enhancing ubiquitin-dependent TGF $\beta$ receptor degradation in breast cancer. Carcinogenesis 34: 874-884.

Iwatsuki, M., K. Mimori, T. Yokobori, H. Ishi, T. Beppu, S. Nakamori, H. Baba, M. Mori (2010) Epithelial-mesenchymal transition in cancer development and its clinical significance. Cancer Sci 101: 293-299.

James, L.R., D. Tang, A. Ingram, H. Ly, K. Thai, L. Cai, J.W. Scholey (2002) Flux through the hexosamine pathway is a determinant of nuclear factor $\mathrm{\kappa B}$-dependent promoter activation. Diabetes 51: 1146-1156.

Jang, M.J., S.H. Baek, J.H. Kim (2011) UCH-L1 promotes cancer metastasis in prostate cancer cells through EMT induction. Cancer Lett 302: 128-135.

Jeon, J.H., H.N. Suh, M.O. Kim, H.J. Han (2013) Glucosamine-induced reduction of integrin $\beta 4$ and plectin complex stimulates migration and proliferation in mouse embryonic stem cells. Stem Cells Dev 22: 2975-2989.

Juttermann, R., E. Li, R. Jaenisch (1994) Toxicity of 5-aza-2'-deoxycytidine to mammalian cells is mediated primarily by covalent trapping of DNA methyltransferase rather than DNA demethylation. Proc Natl Acad Sci USA 91: 11797-11801.

Kahlert, C., S. Lahes, P. Radhakrishnan, S. Dutta, C. Mogler, E. Herpel, K. Brand, G. Steinert, M. Schneider, M. Mollenhauer, et al. (2011) Overexpression of ZEB2 at the invasion front of colorectal cancer is an independent prognostic marker and regulates tumor invasion in vitro. Clin Cancer Res 17: 7654-7663.

Kamigaito, T., T. Okaneya, M. Kawakubo, H. Shimojo, O. Nishizawa, J. Nakayama (2014) Overexpression of O-GlcNAc by prostate cancer cells is significantly associated with poor prognosis of patients. Prostate Cancer Prostatic Dis 17: 18-22.

Khan, M.A., M. Tania, C. Wei, Z. Mei, S. Fu, J. Cheng, J. Xu, J. Fu (2015) Thymoquinone inhibits cancer metastasis by downregulating TWIST1 expression to reduce epithelial to mesenchymal transition. Oncotarget 6: 19580-19591. 
Kim, E.Y., E.H. Jeong, S. Park, H.J. Jeong, I. Edery, J.W. Cho (2012) A role for O-GlcNAcylation in setting circadian clock speed. Genes Dev 26: 490-502.

Kim, Y.J., A. Varki (1997) Perspectives on the significance of altered glycosylation of glycoproteins in cancer. Glycoconj J 14: 569-576.

Knutson, S.K., T.J. Wigle, N.M. Warholic, C.J. Sneeringer, C.J. Allain, C.R. Klaus, J.D. Sacks, A. Raimondi, C.R. Majer, J. Song, et al. (2012) A selective inhibitor of EZH2 blocks H3K27 methylation and kills mutant lymphoma cells. Nat Chem Biol 8: 890-896.

Köbel, M., D. Turbin, S.E. Kalloger, D. Gao, D.G. Huntsman, C.B. Gilks (2011) Biomarker expression in pelvic high-grade serous carcinoma: comparison of ovarian and omental sites. Int J Gynecol Pathol 30: 366-371.

Kondo, K., N. Kohno, A. Yokoyama, K. Hiwada (1998) Decreased MUC1 expression induces E-cadherin-mediated cell adhesion of breast cancer cell lines. Cancer Res 58: 2014-2019.

Koutsaki, M., D.A. Spandidos, A. Zaravinos (2014) Epithelial-mesenchymal transitionassociated miRNAs in ovarian carcinoma, with highlight on the miR-200 family: prognostic value and prospective role in ovarian cancer therapeutics. Cancer Lett 351: 173 181.

Krzeslak, A., E. Forma, M. Bernaciak, H. Romanowicz, M. Brys (2012) Gene expression of $\mathrm{O}$-GlcNAc cycling enzymes in human breast cancers. Clin Exp Med 12: 61-65.

Kurkjian, C., S. Kummar, A.J. Murgo (2008) DNA methylation: its role in cancer development and therapy. Curr Probl Cancer 32: 187-235.

Kwok, W.K., M.-T. Ling, T.-W. Lee, T.C.M. Lau, C. Zhou, X. Zhang, C.W. Chua, K.W. Chan, F.L. Chan, C. Glackin, et al. (2005) Up-regulation of TWIST in prostate cancer and its implication as a therapeutic target. Cancer Res 65: 5153-5162.

Lachner, M., T. Jenuwein (2002) The many faces of histone lysine methylation. Curr Opin Cell Biol 14: 286-298.

Lahat, G., Q.-S. Zhu, K.-L. Huang, S. Wang, S. Bolshakov, J. Liu, K. Torres, R.R. Langley, A.J. Lazar, M.C. Hung, et al. (2010) Vimentin is a novel anti-cancer therapeutic target: insights from in vitro and in vivo mice xenograft studies. PLoS One 5: e10105.

Lamouille, S., J. Xu, R. Derynck (2014) Molecular mechanisms of epithelial-mesenchymal transition. Nat Rev Mol Cell Biol 15: 178-196.

Lehnertz, B., C. Pabst, L. Su, M. Miller, F. Liu, L. Yi, R. Zhang, J. Krosl, E. Yung, J. Kirschner, et al. (2014) The methyltransferase G9a regulates HoxA9-dependent transcription in AML. Genes Dev 28: 317-327.

Lemjabbar-Alaoui, H., A. McKinney, Y.W. Yang, V.M. Tran, J.J. Phillips (2015) Glycosylation alterations in lung and brain cancer. Adv Cancer Res 126: 305-344.

Lester, R.D., M. Jo, V. Montel, S. Takimoto, S.L. Gonias (2007) uPAR induces epithelial-mesenchymal transition in hypoxic breast cancer cells. J Cell Biol 178: 425-436.
Li, H., H. Wang, F. Wang, Q. Gu, X. Xu (2011) Snail involves in the transforming growth factor $\beta 1$-mediated epithelial-mesenchymal transition of retinal pigment epithelial cells. PLoS One 6: e23322.

Li, M.D., H.B. Ruan, M.E. Hughes, J.S. Lee, J.P. Singh, S.P. Jones, M.N. Nitabach, X. Yang (2013) O-GlcNAc signaling entrains the circadian clock by inhibiting BMAL1/CLOCK ubiquitination. Cell Metab 17: 303-310.

Lin, T., A. Ponn, X. Hu, B.K. Law, J. Lu (2010) Requirement of the histone demethylase LSD1 in Snail-mediated transcriptional repression during epithelial-mesenchymal transition. Oncogene 29: 4896-4904.

Ling, Z.-Q., P. Li, M.-H. Ge, X. Zhao, F.-J. Hu, X.H. Fang, Z.-M. Dong, W.-M. Mao (2011) Hypermethylation-modulated down-regulation of $\mathrm{CDH} 1$ expression contributes to the progression of esophageal cancer. Int J Mol Med 27: 625-635.

Lo, H.-W., S.-C. Hsu, W. Xia, X. Cao, J.-Y. Shih, Y. Wei, J.L. Abbruzzese, G.N. Hortobagyi, M.-C. Hung (2007) Epidermal growth factor receptor cooperates with signal transducer and activator of transcription 3 to induce epithelial-mesenchymal transition in cancer cells via up-regulation of TWIST gene expression. Cancer Res 67: 9066-9076.

Love, D.C., J.A. Hanover (2005) The hexosamine signaling pathway: deciphering the "OGlcNAc code". Sci STKE 2005: re13.

Lubas, W.A., D.W. Frank, M. Krause, J.A. Hanover (1997) O-Linked GlcNAc transferase is a conserved nucleocytoplasmic protein containing tetratricopeptide repeats. J Biol Chem 272: 9316-9324.

Luo, J., D.M. Lubaroff, M.J. Hendrix (1999) Suppression of prostate cancer invasive potential and matrix metalloproteinase activity by $\mathrm{E}$ cadherin transfection. Cancer Res 59: 35523556.

Ma, X., H.H. Ezzeldin, R.B. Diasio (2009) Histone deacetylase inhibitors: current status and overview of recent clinical trials. Drugs 69: 1911-1934.

Ma, Z., D.J. Vocadlo, K. Vosseller (2013) Hyper$\mathrm{O}-$ GlcNAcylation is anti-apoptotic and maintains constitutive NF- $\kappa B$ activity in pancreatic cancer cells. J Biol Chem 288: 1512115130.

Mann, B.S., J.R. Johnson, M.H. Cohen, R. Justice, R. Pazdur (2007) FDA approval summary: vorinostat for treatment of advanced primary cutaneous T-cell lymphoma. Oncologist 12: 1247-1252.

Marie-Egyptienne, D.T., I. Lohse, R.P. Hill (2013) Cancer stem cells, the epithelial to mesenchymal transition (EMT) and radioresistance: potential role of hypoxia. Cancer Lett 341: 63-72.

Masuda, T., H. Saito, F. Kaneko, K. Atsukawa, M. Morita, H. Inagaki, N. Kumagai, K. Tsuchimoto, A.H. Ishii (2000) Up-regulation of Ecadherin and I-catenin in human hepatocellular carcinoma cell lines by sodium butyrate and interferon-alpha. In Vitro Cell Dev Biol Anim 36: 387-394.
Mehta, A., H. Herrera, T. Block (2015) Glycosylation and liver cancer. Adv Cancer Res 126: 257-279.

Metzger, E., M. Wissmann, N. Yin, J.M. Muller, R. Schneider, A.H. Peters, T. Gunther, R. Buettner, R. Schule (2005) LSD1 demethylates repressive histone marks to promote androgen-receptor-dependent transcription. Nature 437: 436-439.

Mi, W., Y. Gu, C. Han, H. Liu, Q. Fan, X. Zhang, Q. Cong, W. Yu (2011) O-GlcNAcylation is a novel regulator of lung and colon cancer malignancy. Biochim Biophys Acta 1812: 514519 .

Mikheeva, S.A., A.M. Mikheev, A. Petit, R. Beyer, R.G. Oxford, L. Khorasani, Maxwell, J.-P. , C.A. Glackin, H. Wakimoto, I. González-Herrero, et al. (2010) TWIST1 promotes invasion through mesenchymal change in human glioblastoma. Mol Cancer 9: 194.

Molina-Ortiz, I., R.A. Bartolomé, P. HernándezVaras, G.P. Colo, J. Teixidó (2009) Overexpression of E-cadherin on melanoma cells inhibits chemokine-promoted invasion involving p190RhoGAP/p120ctn-dependent inactivation of RhoA. J Biol Chem 284: $15147-$ 15157.

Morel, A.P., G.W. Hinkal, C. Thomas, F. Fauvet, S. Courtois-Cox, A. Wierinckx, M. Devouassoux-Shisheboran, I. Treilleux, A. Tissier, B. Gras, et al. (2012) EMT inducers catalyze malignant transformation of mammary epithelial cells and drive tumorigenesis towards claudin-low tumors in transgenic mice. PLoS Genet 8: e1002723.

Nagaraj, N.S., P.K. Datta (2010) Targeting the transforming growth factor $-\beta$ signaling pathway in human cancer. Exp Opin Invest Drugs 19: 77-91.

Nam, J.S., Y. Ino, Y. Kanai, M. Sakamoto, S. Hirohashi (2004) 5-aza-2'-deoxycytidine restores the E-cadherin system in E-cadherin-silenced cancer cells and reduces cancer metastasis. Clin Exp Metastasis 21: 49-56.

Nemeth, E.F., L.M. Kosz (1989) Adenine nucleotides mobilize cellular $\mathrm{Ca}^{2+}$ and inhibit parathyroid hormone secretion. Am J Physiol 257: E505-E513.

Nisticò, P., M.J. Bissell, D.C. Radisky (2012) Epithelial-mesenchymal transition: general principles and pathological relevance with special emphasis on the role of matrix metalloproteinases. Cold Spring Harb Perspect Biol 4: a011908.

Ogura, M., T. Uchida, Y. Terui, F. Hayakawa, Y. Kobayashi, M. Taniwaki, Y. Takamatsu, T. Naoe, K. Tobinai, W. Munakata, et al. (2015) Phase I study of OPB-51602, an oral inhibitor of signal transducer and activator of transcription 3, in patients with relapsed/refractory hematological malignancies. Cancer Sci 106: 896-901.

Ohn, T., N. Kedersha, T. Hickman, S. Tisdale, P. Anderson (2008) A functional RNAi screen links O-GlcNAc modification of ribosomal proteins to stress granule and processing body assembly. Nat Cell Biol 10: 1224-1231. 
Okano, M., S. Xie, E. Li (1998) Cloning and characterization of a family of novel mammalian DNA (cytosine-5) methyltransferases. Nat Genet 19: 219-220.

Olivier-Van Stichelen, S., V. Dehennaut, A. Buzy, J.L. Zachayus, C. Guinez, A.M. Mir, I. El Yazidi-Belkoura, M.C. Copin, D. Boureme, D. Loyaux, et al. (2014) O-GlcNAcylation stabilizes $\beta$-catenin through direct competition with phosphorylation at threonine 41. FASEB J 28: 3325-3338.

Olsen, R.R., M.N. Mary-Sinclair, Z. Yin, K.W. Freeman (2015) Antagonizing Bcl-2 family members sensitizes neuroblastoma and Ewing's sarcoma to an inhibitor of glutamine metabolism. PLoS One 10: e0116998.

Pai, H.-C., L.-H. Chang, C.-Y. Peng, Y.-L. Chang, C.-C. Chen, C.-C. Shen, C.-M. Teng, S.-L. Pan (2013) Moscatilin inhibits migration and metastasis of human breast cancer MDAMB-231 cells through inhibition of Akt and Twist signaling pathway. J Mol Med 91: 347356.

Palena, C., D.H. Hamilton (2015) Immune targeting of tumor epithelial-mesenchymal transition via brachyury-based vaccines; in Wang X.-Y., P.B. Fisher (eds): Advances in Cancer Research. Cambridge, Academic Press, chapt 2, pp 69-93.

Park, C.-Y., D.-K. Kim, Y.Y. Sheen (2011a) EW7203, a novel small molecule inhibitor of transforming growth factor- $\beta$ (TGF- $\beta$ ) type I receptor/activin receptor-like kinase-5, blocks TGF- $\beta 1$-mediated epithelial-to-mesenchymal transition in mammary epithelial cells. Cancer Sci 102: 1889-1896.

Park, C.-Y., J.-Y. Son, C.H. Jin, J.-S. Nam, D.-K. Kim, Y.Y. Sheen (2011b) EW-7195, a novel inhibitor of ALK5 kinase inhibits EMT and breast cancer metastasis to lung. Eur J Cancer 47: 2642-2653.

Park, S.Y., H.S. Kim, N.H. Kim, S. Ji, S.Y. Cha, J.G. Kang, I. Ota, K. Shimada, N. Konishi, H.W. Nam, et al. (2010) Snaill is stabilized by OGlcNAc modification in hyperglycaemic condition. EMBO J 29: 3787-3796.

Peng, H., O.A. Carretero, N. Vuljaj, T.-D. Liao, A. Motivala, E.L. Peterson, N.-E. Rhaleb (2005) Angiotensin-converting enzyme inhibitors: a new mechanism of action. Circulation 112: 2436-2445.

Phueaouan, T., P. Chaiyawat, P. Netsirisawan, D. Chokchaichamnankit, P. Punyarit, C. Srisomsap, J. Svasti, V. Champattanachai (2013) Aberrant O-GlcNAc-modified proteins expressed in primary colorectal cancer. Oncol Rep 30: 2929-2936.

Pochec, E., M. Janik, D. Hoja-Lukowicz, P. LinkLenczowski, M. Przybylo, A. Litynska (2013) Expression of integrins $\alpha 3 \beta 1$ and $\alpha 5 \beta 1$ and GlcNAc $\beta 1,6$ glycan branching influences metastatic melanoma cell migration on fibronectin. Eur J Cell Biol 92: 355-362.

Polyak, K., R.A. Weinberg (2009) Transitions between epithelial and mesenchymal states: acquisition of malignant and stem cell traits. Nat Rev Cancer 9: 265-273.
Reka, A.K., R. Kuick, H. Kurapati, T.J. Standiford, G.S. Omenn, V.G. Keshamouni (2011) Identifying inhibitors of epithelial-mesenchymal transition by connectivity-map based systems approach. J Thorac Oncol 6: 1784-1792.

Rodon, J., R. Dienstmann, V. Serra, J. Tabernero (2013) Development of PI3K inhibitors: lessons learned from early clinical trials. Nat Rev Clin Oncol 10: 143-153.

Rodriguez, F.J., L.J. Lewis-Tuffin, P.Z. Anastasiadis (2012) E-cadherin's dark side: possible role in tumor progression. Biochim Biophys Acta 1826: 23-31.

Rosenfeld, H., J. Roberts (1981) Enhancement of antitumor activity of glutamine antagonists 6-diazo-5-oxo-L-norleucine and acivicin in cell culture by glutaminase-asparaginase. Cancer Res 41: 1324-1328.

Ruan, H.B., Y. Nie, X. Yang (2013) Regulation of protein degradation by O-GlcNAcylation: crosstalk with ubiquitination. Mol Cell Proteomics 12: 3489-3497.

Sadler, N.M., B.R. Harris, B.A. Metzger, J. Kirshner (2013) N-cadherin impedes proliferation of the multiple myeloma cancer stem cells. Am J Blood Res 3: 271-285.

Sanchez-Tillo, E., Y. Liu, O. de Barrios, L. Siles, L. Fanlo, M. Cuatrecasas, D.S. Darling, D.C. Dean, A. Castells, A. Postigo (2012) EMT-activating transcription factors in cancer: beyond EMT and tumor invasiveness. Cell Mol Life Sci 69: 3429-3456.

Satelli, A., S. Li (2011) Vimentin in cancer and its potential as a molecular target for cancer therapy. Cell Mol Life Sci 68: 3033-3046.

Schust, J., B. Sperl, A. Hollis, T.U. Mayer, T. Berg (2006) Stattic: a small-molecule inhibitor of STAT3 activation and dimerization. Chem Biol 13: 1235-1242.

Shaker, S., M. Bernstein, R.L. Momparler (2004) Antineoplasticaction of 5-aza-2' -deoxycytidine (Dacogen) and depsipeptide on Raji lymphoma cells. Oncol Rep 11: 1253-1256.

Shelton, L.M., L.C. Huysentruyt, T.N. Seyfried (2010) Glutamine targeting inhibits systemic metastasis in the VM-M3 murine tumor model. Int J Cancer 127: 2478-2485.

Shepherd, F.A., J. Rodrigues Pereira, T. Ciuleanu, E.H. Tan, V. Hirsh, S. Thongprasert, D. Campos, S. Maoleekoonpiroj, M. Smylie, R., Martins, et al. (2005) Erlotinib in previously treated non-small-cell lung cancer. New Engl J Med 353: 123-132.

Sheppard, D. (2005) Integrin-mediated activation of latent transforming growth factor beta. Cancer Metastasis Rev 24: 395-402.

Shi, Y., F. Lan, C. Matson, P. Mulligan, J.R. Whetstine, P.A. Cole, R.A. Casero (2004) Histone demethylation mediated by the nuclear amine oxidase homolog LSD1. Cell 119: 941-953.

Shintani, Y., Y. Fukumoto, N. Chaika, P.M. Grandgenett, M.A. Hollingsworth, M.J. Wheelock, K.R. Johnson (2008) ADH-1 suppresses $\mathrm{N}$-cadherin-dependent pancreatic cancer progression. Int J Cancer 122: 71-77.

Shiota, M., E. Kashiwagi, A. Yokomizo, A. Takeuchi, T. Dejima, Y. Song, K. Tatsugami, J.
Inokuchi, T. Uchiumi, S. Naito (2013) Interaction between docetaxel resistance and castration resistance in prostate cancer: implications of Twist1, YB-1, androgen receptor. Prostate 73: 1336-1344.

Shiota, M., A. Yokomizo, Y. Tada, J. Inokuchi, E. Kashiwagi, D. Masubuchi, M. Eto, T. Uchiumi, S. Naito (2010) Castration resistance of prostate cancer cells caused by castration-induced oxidative stress through Twist 1 and androgen receptor overexpression. Oncogene 29: 237-250.

Shiota, M., A. Yokomizo, A. Takeuchi, K. Imada, E. Kashiwagi, Y. Song, J. Inokuchi, K. Tatsugami, T. Uchiumi, S. Naito (2014) Inhibition of protein kinase $\mathrm{C} /$ Twist1 signaling augments anticancer effects of androgen deprivation and enzalutamide in prostate cancer. Clin Cancer Res 20: 951-961.

Siddiquee, K., S. Zhang, W.C. Guida, M.A. Blaskovich, B. Greedy, H.R. Lawrence, M.L.R. Yip R. Jove, M.M. McLaughlin, N.J. Lawrence, et al. (2007) Selective chemical probe inhibitor of Stat3, identified through structure-based virtual screening, induces antitumor activity. Proc Natl Acad Sci USA 104: 7391-7396.

Singh, R.P., K. Raina, G. Sharma, R. Agarwal (2008) Silibinin inhibits established prostate tumor growth, progression, invasion, metastasis and suppresses tumor angiogenesis and epithelial-mesenchymal transition in transgenic adenocarcinoma of the mouse prostate model mice. Clin Cancer Res 14: 7773-7780.

Soto-Reyes, E., F. Recillas-Targa (2010) Epigenetic regulation of the human $\mathrm{p} 53$ gene promoter by the CTCF transcription factor in transformed cell lines. Oncogene 29: 2217-2227.

Sparano, J.A., P. Bernardo, P. Stephenson, W.J. Gradishar, J.N. Ingle, S. Zucker, N.E. Davidson (2004) Randomized phase III trial of marimastat versus placebo in patients with metastatic breast cancer who have responding or stable disease after first-line chemotherapy: Eastern Cooperative Oncology Group trial E2196. J Clin Oncol 22: 4683-4690.

Srivastava, R.K., S.-N. Tang, W. Zhu, D. Meeker, S. Shankar (2011) Sulforaphane synergizes with quercetin to inhibit self-renewal capacity of pancreatic cancer stem cells. Front Biosci 3: 515-528.

Struhl, K. (1998) Histone acetylation and transcriptional regulatory mechanisms. Genes Dev 12: 599-606.

Subramanian, G., R.E. Schwarz, L. Higgins, G. McEnroe, S. Chakravarty, S. Dugar, M. Reiss (2004) Targeting endogenous transforming growth factor beta receptor signaling in SMAD4-deficient human pancreatic carcinoma cells inhibits their invasive phenotype1. Cancer Res 64: 5200-5211.

Tachibana, M., K. Sugimoto, M. Nozaki, J. Ueda, T. Ohta, M. Ohki, M. Fukuda, N. Takeda, H. Niida, H. Kato, et al. (2002) G9a histone methyltransferase plays a dominant role in euchromatic histone $\mathrm{H} 3$ lysine 9 methylation and is essential for early embryogenesis. Genes Dev 16: 1779-1791. 
Takai, N., J.C. Desmond, T. Kumagai, D. Gui, J.W. Said, S. Whittaker, I. Miyakawa, H.P. Koeffler (2004) Histone deacetylase inhibitors have a profound antigrowth activity in endometrial cancer cells. Clin Cancer Res 10: 1141-1149.

Tanaka, H., E. Kono, C.P. Tran, H. Miyazaki, J. Yamashiro, T. Shimomura, L. Fazli, R. Wada, J. Huang, R.L. Vessella, et al. (2010) Monoclonal antibody targeting of $\mathrm{N}$-cadherin inhibits prostate cancer growth, metastasis and castration resistance. Nat Med 16: 1414-1420.

Tania, M., M.A. Khan, J. Fu (2014) Epithelial to mesenchymal transition inducing transcription factors and metastatic cancer. Tumour Biol 35: 7335-7342.

Teng, Y., X. Li (2014) The roles of HLH transcription factors in epithelial mesenchymal transition and multiple molecular mechanisms. Clin Exp Metastasis 31: 367-377.

Thangavelu, K., Q.Y. Chong, B.C. Low, J. Sivaraman (2014) Structural basis for the active site inhibition mechanism of human kidney-type glutaminase (KGA). Sci Rep 4: 3827.

Tiwari, N., A. Gheldof, M. Tatari, G. Christofori (2012) EMT as the ultimate survival mechanism of cancer cells. Semin Cancer Biol 22: 194-207.

Tran, P.T., E.H. Shroff, T.F. Burns, S. Thiyagarajan, S.T. Das, T. Zabuawala, J. Chen, Y.-J. Cho, R. Luong, P. Tamayo, et al. (2012) Twist1 suppresses senescence programs and thereby accelerates and maintains mutant Kras-induced lung tumorigenesis. PLoS Genet 8: e1002650.

van Denderen, B.J.W., E.W. Thompson (2013) Cancer: the to and fro of tumour spread. Nature 493: 487-488.

Vedadi, M., D. Barsyte-Lovejoy, F. Liu, S. RivalGervier, A. Allali-Hassani, V. Labrie, T.J. Wigle, P.A. Dimaggio, G.A. Wasney, A. Siarheyeva, et al. (2011) A chemical probe selectively inhibits G9a and GLP methyltransferase activity in cells. Nat Chem Biol 7: 566-574.

Voulgari, A., A. Pintzas (2009) Epithelial-mesenchymal transition in cancer metastasis: mechanisms, markers and strategies to overcome drug resistance in the clinic. Biochim Biophys Acta 1796: 75-90.

Wagner, T., M. Jung (2012) New lysine methyltransferase drug targets in cancer. Nat Biotechnol 30: 622-623.

Wang, K.C., Y.W. Yang, B. Liu, A. Sanyal, R. Corces-Zimmerman, Y. Chen, B.R. Lajoie, A. Protacio, R.A. Flynn, R.A. Gupta, et al. (2011) A long noncoding RNA maintains active chromatin to coordinate homeotic gene expression. Nature 472: 120-124.

Warita, K., T. Warita, C.H. Beckwitt, M.E. Schurdak, A. Vazquez, A. Wells, Z.N. Oltvai (2014) Statin-induced mevalonate pathway inhibition attenuates the growth of mesenchymallike cancer cells that lack functional E-cadherin mediated cell cohesion. Sci Rep 4: 7593.

Witta, S.E., R.M. Gemmill, F.R. Hirsch, C.D. Coldren, K. Hedman, L. Ravdel, B. Helfrich, R. Dziadziuszko, D.C. Chan, M. Sugita, et al. (2006) Restoring E-cadherin expression increases sensitivity to epidermal growth factor receptor inhibitors in lung cancer cell lines. Cancer Res 66: 944-950.

Witta, S.E., R.M. Jotte, K. Konduri, M.A. Neubauer, A.I. Spira, R.L. Ruxer, M. Varella-Garcia, P.A. Bunn, F.R. Hirsch (2012) Randomized phase II trial of erlotinib with and without entinostat in patients with advanced non-smallcell lung cancer who progressed on prior chemotherapy. J Clin Oncol 30: 2248-2255.

Wong, A.S.T., B.M. Gumbiner (2003) Adhesionindependent mechanism for suppression of tumor cell invasion by E-cadherin. J Cell Biol 161: 1191-1203.

Wu, K.J., J. Zeng, G.D. Zhu, L.L. Zhang, D. Zhang, L. Li, J.H. Fan, X.Y. Wang, D.L. He (2009) Silibinin inhibits prostate cancer invasion, motility and migration by suppressing vimentin and MMP-2 expression. Acta Pharmacol Sin 30: 1162-1168.

Wu, M.Z., Y.P. Tsai, M.H. Yang, C.H. Huang, S.Y. Chang, C.C. Chang, S.C. Teng, K.J. Wu (2011) Interplay between HDAC3 and WDR 5 is essential for hypoxia-induced epithelial-mesenchymal transition. Mol Cell 43: 811-822.

Xu, Y., S.H. Lee, H.S. Kim, N.H. Kim, S. Piao, S.H Park, Y.S. Jung, J.I. Yook, B.J. Park, N.C. Ha (2010) Role of CK1 in GSK3 $\beta$-mediated phosphorylation and degradation of snail. Oncogene 29: 3124-3133.

Yadav, A., B. Kumar, J. Datta, T.N. Teknos, P. Kumar (2011) IL-6 promotes head and neck tumor metastasis by inducing epithelial-mesenchymal transition via the JAK-STAT3-SNAIL signaling pathway. Mol Cancer Res 9: 16581667.

Yang, F., L. Sun, Q. Li, X. Han, L. Lei, H. Zhang, Y. Shang (2012) SET8 promotes epithelialmesenchymal transition and confers TWIST dual transcriptional activities. EMBO J 31: 110-123.

Yang, J., S.A. Mani, J.L. Donaher, S. Ramaswamy, R.A. Itzykson, C. Come, P. Savagner, I. Gitelman, A. Richardson, R.A. Weinberg (2004) Twist, a master regulator of morphogenesis, plays an essential role in tumor metastasis. Cell 117: 927-939.

Yang, W.H., J.E. Kim, H.W. Nam, J.W. Ju, H.S. Kim, Y.S. Kim, J.W. Cho (2006) Modification of p53 with O-linked $\mathrm{N}$-acetylglucosamine regulates p53 activity and stability. Nat Cell Biol 8: 1074-1083.

Yang, W.H., S.Y. Park, H.W. Nam, H. Kim do, J.G. Kang, E.S. Kang, Y.S. Kim, H.C. Lee, K.S. Kim, J.W. Cho (2008) NFKB activation is associated with its O-GlcNAcylation state under hyperglycemic conditions. Proc Natl Acad Sci USA 105: 17345-17350.

Yang, W.H., Y.H. Su, W.H. Hsu, C.C. Wang, J.L. Arbiser, M.H. Yang (2016) Imipramine blue halts head and neck cancer invasion through promoting F-box and leucine-rich repeat protein 14-mediated Twist1 degradation. Oncogene 35: 2287-2298.

Yehezkel, G., L. Cohen, A. Kliger, E. Manor, I. Khalaila (2012) $O$-linked $\beta$ - $N$-acetylglucosaminylation (O-GlcNAcylation) in primary and metastatic colorectal cancer clones and ef- fect of $N$-acetyl- $\beta$-D-glucosaminidase silencing on cell phenotype and transcriptome. J Biol Chem 287: 28755-28769.

Yilmaz, M., G. Christofori (2009) EMT, the cytoskeleton, and cancer cell invasion. Cancer Metastasis Rev 28: 15-33.

Yoshiura, K., Y. Kanai, A. Ochiai, Y. Shimoyama, T. Sugimura, S. Hirohashi (1995) Silencing of the E-cadherin invasion-suppressor gene by CpG methylation in human carcinomas. Proc Natl Acad Sci USA 92: 7416-7419.

Yu, M., A. Bardia, B.S. Wittner, S.L. Stott, M.E. Smas, D.T. Ting, S.J. Isakoff, J.C. Ciciliano, M.N. Wells, A.M. Shah, et al. (2013) Circulating breast tumor cells exhibit dynamic changes in epithelial and mesenchymal composition. Science 339: 580-584.

Yuan, J., F. Zhang, R. Niu (2015) Multiple regulation pathways and pivotal biological functions of STAT3 in cancer. Sci Rep 5: 17663.

Yuan, Y., Q. Wang, J. Paulk, S. Kubicek, M.M. Kemp, D.J. Adams, A.F. Shamji, B.K. Wagner, S.L. Schreiber (2012) A small-molecule probe of the histone methyltransferase G9a induces cellular senescence in pancreatic adenocarcinoma. ACS Chem Biol 7: 1152-1157.

Zachara, N.E., N. O'Donnell, W.D. Cheung, J.J. Mercer, J.D. Marth, G.W. Hart (2004) Dynamic $O$-GlcNAc modification of nucleocytoplasmic proteins in response to stress: a survival response of mammalian cells. J Biol Chem 279: 30133-30142.

Zhai, B., H.X. Yan, S.Q. Liu, L. Chen, M.C. Wu, H.Y. Wang (2008) Reduced expression of E-cadherin/catenin complex in hepatocellular carcinomas. World J Gastroenterol 14: 5665-5673.

Zheng, H., Y. Kang (2014) Multilayer control of the EMT master regulators. Oncogene 33: 1755-1763.

Zheng, X., J.L. Carstens, J. Kim, M. Scheible, J. Kaye, H. Sugimoto, C.-C. Wu, V.S. LeBleu, R. Kalluri (2015) Epithelial-to-mesenchymal transition is dispensable for metastasis but induces chemoresistance in pancreatic cancer. Nature 527: 525-530.

Zhou, B.P., J. Deng, W. Xia, J. Xu, Y.M. Li, M. Gunduz, M.C. Hung (2004) Dual regulation of Snail by GSK-3 $\beta$-mediated phosphorylation in control of epithelial-mesenchymal transition. Nat Cell Biol 6: 931-940.

Zhu, Q., L. Zhou, Z. Yang, M. Lai, H. Xie, L. Wu, C. Xing, F. Zhang, S. Zheng (2012) O-GlcNAcylation plays a role in tumor recurrence of hepatocellular carcinoma following liver transplantation. Med Oncol 29: 985-993.

Zhuo, W., Y. Wang, X. Zhuo, Y. Zhang, X. Ao, Z. Chen (2008a) Knockdown of Snail, a novel zinc finger transcription factor, via RNA interference increases A549 cell sensitivity to cisplatin via $\mathrm{JNK} /$ mitochondrial pathway. Lung Cancer 62: 8-14.

Zhuo, W.L., Y. Wang, X.L. Zhuo, Y.S. Zhang, Z.T. Chen (2008b) Short interfering RNA directed against TWIST, a novel zinc finger transcription factor, increases A549 cell sensitivity to cisplatin via MAPK/mitochondrial pathway. Biochem Biophys Res Commun 369: 1098-1102. 